\title{
PENGGUNAAN BAHASA PADA MASYARAKAT MULTIETNIS DI KARANG TALIWANG MATARAM
}

\author{
Baiq Rismarini Nursaly \\ STKIP Hamzanwadi Mataram \\ rismarini09@gmail.com
}

\begin{abstract}
Karang Taliwang is one of regions in the district of Cakranegara, Kota Mataram, West Nusa Tenggara Province. Here live three language communities. They are Sasak, Bali, and Sumbawa. Each of them use their own language to communicate with their community but do code mixing when communicate with other language communities. Their choice of language depends on some factors among other things; domain, place, situation, participant and purpose as said by Fishman," who speak, what language, to whom, when, and to what end".
\end{abstract}

Keywords: language used, language communities

\section{PENDAHULUAN}

Pulau Lombok yang terrletak di antara Pulau Bali dan Pulau Sumbawa menyebabkan masyarakatnya menjadi multietnis. Sebagian besar penduduk Pulau Lombok adalah etnis Sasak yang merupakan penduduk asli, namun karena letaknya yang diapit oleh pulau Sumbawa dan pulau Bali menyebabkan etnis Bali dan etnis Sumbawa menempati posisi kedua dan ketiga dalam jumlah penduduk di pulau Lombok.

Salah satu wilayah di Kota Mataram adalah Kecamatan Cakranegara yang terdiri dari 10 kelurahan. Salah satu dari kelurahan di wilayah kecamatan ini yaitu Kelurahan Karang Taliwang wilayahnya sebagian besar didiami oleh suku Sumbawa, suku Bali dan suku Sasak yang hidup secara berdampingan dan harmonis. Hal ini menimbulkan adanya pergaulan atau komunikasi antaretnis dalam frekuensi yang cukup tinggi dan dalam waktu yang relatif panjang, Hal ini menjadi menarik untuk dicermati secara sosiolinguistis dengan kajian Etnografi komunikasi. Etnografi komunikasi adalah bagian dari sosiolinguistik yang memerikan suatu masyarakat atau etnik, etnografi tentang suatu bahasa memfokuskan pada pemakaian bahasa dalam $\begin{array}{lcr}\text { pertuturan } & \text { atau } & \text { komunikasi } \\ \text { menggunakan } & \text { bahasa. } & \text { Sementara } \\ \text { sosiolinguistik } & \text { sendiri } & \text { lebih } \\ \text { mengungkapkan } & \text { pemakaian } & \text { bahasa }\end{array}$ bukan struktur bahasa. Etnografi komunikasi merupakan gambaran dari keseluruhan Faktor yang terkait dengan pemahaman bagaimana suatu kejadian komunikasi tertentu dapat mencapai tujuannya (Wardhaugh 1986, 238-241). Studi etnografi komunikasi adalah salah satu bentuk penelitian kualitatif yang mengkhususkan pada penemuan berbagai pola komunikasi yang digunakan manusia dalam suatu masyarakat tutur (Saville-Troike 2003, 2-3). Pola-pola komunikasi tersebut ditemukan berdasarkan analisis komponen tutur yang dipengaruhi oleh aspek-aspek; linguistik, interaksi sosial, dan kebudayaan dalam pola komunikasi.

\section{TEORI}

Hymes (1964a, 4) mengemukakan istilah Ethnography of Speaking yang merupakan penggabungan dari etnologi dan linguistik yang mengkaji situasi, penggunaan, pola, dan fungsi berbicara sebagai suatu aktifitas tersendiri. Istilah itu kemudian dirubah sendiri oleh Hymes menjadi Ethnography of Communication untuk menganalisis perilaku komunikasi manusia yang berhubungan erat dengan kebudayaan. 
Paulston and Tucker (2003, 41-46); Wardhaugh (1986, 238-241) yang mengutip dari Hymes (1974) mengemukakan bahwa kerangka etnografis mempertimbangkan berbagai faktor dalam berbicara atau memakai bahasa. Untuk mempermudah mengingat faktor-faktor tersebut sehingga Hymes membuat akronim SPEAKING yaitu:

1. S: Situation/setting (situasi) 'tempat dan suasana tuturan'

2. P: Participant (peserta tutur)' pembicara yang dituju, pendengar/penerima'

3. E: Ends (akhir) 'hasil/tujuan tuturan'

4. A: Act sequence (urutan tindakan) 'bentuk pesan dan isi pesan'

5. K: Key (kunci)'nada tutur'

6. I: Instrumentalities 'sarana tutur'

7. N: Norms (norma-norma) 'norma interaksi dan interpretasi'

8. G: Genres 'jenis tuturan' (SavilleTroike 2003,10).

Fishman merumuskannya dengan lebih sederhana menjadi who speak, what language, to whom, when, and to what end. Dalam tulisan ini permasalahan yang akan dijabarkan adalah Bagaimana penggunaan bahasa pada masyarakat multibahasa dan multietnis di Kelurahan Karang Taliwang, Kecamatan Cakranegara, Kota Mataram, Provinsi NTB pada ranah-ranah; keluarga, pendidikan, pemerintahan, keagamaan, dan pergaulan.

\section{METODE}

Penelitian ini adalah penelitian deskriptif kualitatif dengan fokus kajian etnografi komunikasi yang menyajikan data-data berupa data verbal (oral) dari komunikasi antara dua orang atau lebih pada situasi formal maupun nonformal di lokasi penelitian. Lokasi penelitian adalah Kelurahan Karang Taliwang, Kecamatan Cakranegara, Kota Mataram, Provinsi Nusa Tenggara Barat. Sumber data penelitian ini didapatkan melalui pengamatan secara langsung proses komunikasi dalam komunitas

Metode pengumpulan data yang digunakan adalah metode simak, dan cakap (Mahsun 2011, 93-116) dimana metode menyimak adalah; memperoleh data dengan menyimak penggunaan bahasa secara lisan maupun tertulis. Kemudian metode cakap, yaitu metode pengumpulan data dengan melakukan percakapan antara peneliti dengan yang diteliti, dimana terjadi kontak diantara mereka sehingga datanya berbentuk bahasa lisan. Analisis data dalam tulisan ini menggunakan metode etnografi komunikasi Hymes (1964a, 13); Schiffrin (1994, 141-42); Duranti (1998, 221) yang dikenal dengan istilah SPEAKING pada ranahranah; keluarga, pendidikan, pemerintahan, keagamaan, dan pergaulan.

\section{HASIL DAN PEMBAHASAN}

Data Kecamatan Cakranegara tahun 2013 menyatakan bahwa, Kelurahan Karang Taliwang terdiri dari 3 lingkungan yaitu; Lingkungan Karang Taliwang, Karang Jero dan Karang Bagu dengan luas wilayah $61.566 \mathrm{Ha}$ dengan jumlah penduduk 6307 jiwa. Dari keseluruhan jumlah tersebut tigaperempatnya adalah etnis Sumbawa (4.144 jiwa) tinggal di Lingkungan Karang Taliwang, sisanya terbagi menjadi dua, setengahnya adalah etnis Sasak (1149 jiwa) yang mendiami Lingkungan Karang Bagu, dan etnis Bali (1014 jiwa) berdomisili di Lingkungan Karang Jero.

\section{Ranah Keluarga}

Pada ranah ini masyarakat Kelurahan Karang Taliwang menggunakan bahasa etnis masing-masing yang artinya etnis Sumbawa memakai Bahasa Sumbawa, dimana penuturnya menyebutkan bahwa bahasa Sumbawa yang mereka gunakan sebagai Bahasa Taliwang. Taliwang sendiri adalah nama sebuah kecamatan di wilayah Kabupaten Sumbawa Barat. Etnis 
Sasak menggunakan Bahasa Sasak, dan etnis Bali menggunakan Bahasa Bali. Secara umum masyarakatnya masih sangat kuat menunjukkan etnis mereka masing-masing dengan tetap mempertahankan bahasa mereka. Sebagian besar informan dari etnis Sumbawa menceritakan tentang kekerabatannya dengan pihak keluarga kerajaan Sumbawa. Identitas etnis ini sangat kental dipertunjukkan oleh generasi yang lebih tua sehingga dalam ranah keluarga mereka selalu menggunakan Bahasa Sumbawa, sementara untuk generasi yang lebih muda walaupun tetap menggunakan Bahasa Sumbawa namun seringkali muncul campur kode dengan Bahasa Indonesia maupun Bahasa Sasak.

Informan penutur Bahasa Bali juga menggunakan Bahasa Bali untuk berkomunikasi dalam ranah keluarga, merekapun mempertahankan identitas etnisnya dengan tetap memelihara dan menggunakan bahasanya. Tidak seperti generasi yang lebih muda di etnis Sumbawa yang seringkali bercampur kode menggunakan Bahasa Indonesia dan Bahasa Sasak. Etnis Bali jarang sekali melakukan campur kode dengan bahasa Sasak, mereka bercampur kode dengan bahasa Indonesia, walaupun hampir seluruh penduduk kelurahan Karang Taliwang paham dan mampu menggunakan Bahasa Sasak.

Sementara informan dari penutur Bahasa Sasak dalam ranah keluarga otomatis menggunakan Bahasa Sasak. Kalaupun muncul campur kode, mereka hanya bercampur kode dengan Bahasa Indonesia, hal ini disebabkan karena mereka memang tidak terlalu paham dan tidak mampu menggunakan Bahasa Sumbawa maupun Bahasa Bali. Seperti pada percakapan di bawah ini.

Peristiwa Tutur I

Ranah : Keluarga etnis Sasak

Lokasi : Halaman rumah

Kode Tutur : Bahasa Sasak Bahasa Indonesia
Partisipan : A (ibu berusia 38 tahun) B (anak perempuan berusia 8 tahun)

Tujuan tuturan: Seorang ibu yang meminta anaknya untuk membeli garam ke warung.

A : Inah, ... ooo Inah, lite semendak, tulung Inaq

(Inah ... ooo Inah, kemarilah sebentar, bantu Ibu)

B : Aro ..Inaq jak arak apa, nyekengke maen ne

(Ah.. ibu ini ada apa sih, ini saya sedang bermain)

A : Semendak doang, beliang Inaq sie lek warung bu Made ndeh, pesu anak inaq jak

(Sebentar saja, belikan ibu garam di warung bu Made ya, anak ibu yang baik)

B : (Sambil terengah-engah karena berlari) "Inaq ndek arak sie lek warung bu Made 'habis' unin".

(Ibu tidak ada garam di warung bu Made,"habis" katanya)

A : Aok wah aneh, terima kasih anak solah, lemaq wah inaq meli lek peken, nane inaq ngendeng sekejik lek papuq Salbiah.

(Ya sudah, terima kasih anak cantik, besok ibu akan membelinya di pasar, sekarang ibu akan minta sedikit garam di nenek Salbiah)

Peristiwa Tutur I terjadi di halaman rumah sebuah keluaraga dari etnis Sasak, percakapan antara seorang ibu dengan anak perempuannya yang masih kecil, percakapan dilakukan dalam suasana yang akrab dan penuh kasih sayang, yang ditandai dengan kata-kata "pesu, anaq inaq, anaq solah "yang berturut-turut berarti," anak baik, anak ibu, dan anak cantik". Katakata tersebut digunakan si ibu untuk membujuk anaknya yang awalnya terlihat enggan, agar mau melakukan permintaannya, yang akhirnya memang membuat anaknya mematuhi apa yang diperintahkannya.

Dalam percakapan tersebut juga terjadi campur kode, dimana Bahasa Sasak yang digunakan bercampur 
dengan beberapa kosa kata Bahasa Indonesia seperti "habis dan terima kasih'. Sebenarnya terdapat padanan untuk kedua kata tersebut dalam Bahasa Sasak yaitu; "bih dan tampi asih", namun si anak tetap menggunakan kata "habis" untuk menerangkan apa yang dikatakan oleh pemilik warung yang berasal dari etnis Bali.

\section{Ranah Pendidikan}

Pada ranah ini masyarakat Karang Taliwang biasanya menggunakan bahasa Indonesia terutama dengan teman-teman yang berbeda etnis dan guru-guru, kepala sekolah, serta pegawai, namun akan melakukan campur kode antara bahasa Indonesia dan bahasa etnisnya masing-masing jika berbicara dengan teman-teman yang berasal dari etnis yang sama. Pada peristiwa tutur II, para partisipan menggunakan bahasa Sumbawa, bahasa Sasak dan bahasa Indonesia terjadi di salah satu Sekolah Dasar Negeri yang ada di wilayah Karang Taliwang.

Peristiwa Tutur II

$\begin{array}{ll}\text { Ranah } & \text { : Pendidikan } \\ \text { Lokasi } & \text { : Sekolah Dasar } \\ \text { Kode Tutur } & \text { Bahasa Sumbawa } \\ & \text { Bahasa Sasak } \\ & \text { Bahasa Indonesia }\end{array}$

Partisipan : A (orang tua siswa, seorang ibu berusia 40 tahun etnis Sumbawa) B (wanita, guru kelas I SD berusia 35 tahun etnis Sasak)

Tujuan tuturan: Pembicaraan sebelum penerimaan raport semester ganjil dan Guru menjelaskan tentang pentingnya orang tua mengawasi anaknya belajar di rumah

A : Halo, Assalamualaikum bu guru, sibuk.

(Halo, Assalamualaikum bu guru, apakah sedang sibuk?)
B : Waalaikum salam tumben bu, arak napi?

(Waalaikum salam, tumben bu, ada keperluan apa?)

A : Nonyak, iya kujalan-jalan, kutulung berisi rapot ndek roa, ndek tama kelas ode-ode?

(Tidak ada apa-apa, ini saya hanya jalan-jalan, mau saya bantu mengisi rapor tapi tidak bisa, apakah anak-anak tidak masuk kelas?)

B : Ndek, Odi jangan lari-lari nanti jatuh! (Sambil berteriak melarang seorang murid yang sedang berlari kencang ke arahnya)

(Tidak, Odi jangan berlari nanti jatuh!)

A : Mele kutulung ndek roa, sengaja kubekedek loka.

(Saya ingin menolong, tapi tidak bisa, jadi sengaja ke sini untuk bermain saja.)

B : Silak-silak masuk dulu.

(Silahkan masuk dulu)

B : (Di dalam kelas guru berbicara kepada para orang tua siswa) "Bagi siswa yang masih kurang atau nilainya belum terpenuhi yaitu masih kurang dari KKM, sekolah mohon bantuan pada Bapak/Ibu untuk mengawasi putra-putrinya ketika siswa belajar di rumah, karena pendidikan tidak dapat diserahkan sepenuhnya kepada guru di sekolah, jadi yang berperan paling besar bagi siswa adalah pendidikan di rumah".

Peristiwa tutur di atas terjadi di sebuah Sekolah Dasar yang berlokasi di dalam Lingkungan Karang Taliwang. Partisipan adalah A salah satu orang tua siswa yang adalah penutur Bahasa Sumbawa dengan B guru kelas I SD yang adalah penutur Bahasa Sasak. Situasi tuturan adalah resmi dan tidak resmi, pada saat masih di luar kelas suasananya tidak resmi, namun ketika para orang tua siswa sudah masuk ke dalam kelas untuk menerima rapor anak-anak mereka, B memberikan 
beberapa informasi dan permohonan bantuan kepada orang tua siswa untuk mengawasi pembelajaran terhadap anak mereka saat berada di rumah.

Pada saat A yang akan mengambil rapor anaknya menegur guru di luar kelas dia menggunakan bahasa yang akrab karena mereka berdua sudah saling mengenal. A mengucapkan salam dan langsung berbicara menggunakan Bahasa Indonesia," Halo, Assalamualaikum bu guru, sibuk?" B menjawab salamnya dan berbicara menggunakan Bahasa Sasak, "Waalaikum salam tumben bu, arak napi?" dijawab kembali oleh A dalam Bahasa Sumbawa," Nonyak, iya kujalan-jalan, kutulung berisi rapot ndek roa, ndek tama kelas ode-ode?" A menjawab lagi menggunakan Bahasa Sasak,"Ndek" namun langsung beralih kode menggunakan Bahasa Indonesia ketika ada seorang murid yang berlari kencang ke arahnya," Odi jangan larilari nanti jatuh!" Hal itu terjadi karena guru tersebut ingin agar muridnya memperhatikan dan segera menghentikan kegiatannnya yang berbahaya tersebut.

\section{Ranah Pemerintahan}

Peristiwa Tutur III

Ranah : Pemerintahan

Lokasi: Puskesmas Karang Taliwang

Kode Tutur : Bahasa Indonesia

Bahasa Sumbawa

Partisipan : A (seorang ibu penduduk asli Karang Taliwang pengunjung puskesmas berusia 40 tahun)

B (seorang perawat yang berasal dari pulau Sumbawa berusia 25 tahun)

Tujuan tutur : A meminta B untuk datang ke rumahnya memeriksa pasien.

A : Assalamualaikum Fitri, mau ngomong sebentar, nanti siang pulang dari puskesmas datang ke rumah kontrol nenek sebentar ya, ini Mamak bawakan nasi taruh ya.
B : Waalaikum salam, e..e mamak repot-repot. (Waalaikum salam, e..e mamak kok merepotkan.)

A : Lok ang aneh becat ku belangan taruh nasinya dulu sama airnya, nanti tidak sempat beli. (tidak apaapa, ambil ini saya mau segera pergi, simpan dulu nasi dan airnya, nanti tidak sempat pergi untuk membeli makan)

B : Bisa beli di depan (Saya bisa membeli di warung depan Puskesmas)

A : Yaok aneh wah ubak nanti jam berapa pulang? (ayolah ambil), nanti jam berapa pulang?)

B : Jam 2 pulangnya.

A : Bisa ngontrol kalau jam 2? Cuma nensi sama lihat keadaannya saja ya, biar mamak tidak capek ke puskesmas soalnya nenek itu berat.

B : Iya mamak, terima kasih.

A : Aok aneh. (iyalah.)

Peristiwa tutur ini terjadi di sebuah Puskesmas di Wilayah Karang Taliwang antara seorang pengunjung Puskesmas dengan seorang perawat (pegawai Puskesmas). Situasi pertuturan cukup resmi karena terjadi pada salah satu kantor pemerintahan. Kode yang digunakan pada awalnya adalah Bahasa Indonesia yang kemudian oleh penutur A dicampur dengan Bahasa Sumbawa karena kebetulan B (perawat) berasal dari pulau Sumbawa. Penutur A yang merasa cukup kenal dan akrab dengan penutur $\mathrm{B}$ berusaha mengajak penutur B untuk berbicara dalam Bahasa Sumbawa, namun penutur B sampai pertuturan berakhir tetap menjawab menggunakan Bahasa Indonesia. Hal tersebut terjadi karena B memperlihatkan kesopanannya terhadap A, kemudian B dengan tersamar mengingatkan kepada A bahwa, walaupun mereka cukup akrab, namun lokasi tuturan mereka adalah di kantor, sehingga sebaiknya menggunakan Bahasa yang resmi, agar orang-orang di sekitar mereka yang kebetulan tidak mengerti Bahasa 
Sumbawa mengetahui apa yang diperbincangkan, dan yang terakhir adalah B sengaja tidak menjawab menggunakan Bahasa Sumbawa karena ada kecenderungan bahwa orang Sumbawa yang tinggal atau menetap untuk keperluan bekerja atau sekolah di Mataram (ibukota Provinsi NTB) merasa enggan menggunakan Bahasa Sumbawa dan beralih kode menggunakan Bahasa Indonesia atau Bahasa Sasak.

\section{Ranah Keagamaan \\ Peristiwa Tutur IV \\ Pembukaan acara pengajian bulanan ibu-ibu warga Karang Taliwang dan qasidahan.

$\begin{array}{lll}\text { Ranah } & \text { : Keagamaan } & \\ \text { Lokasi } & \text { : Rumah salah satu } \\ & \text { warga } & \\ \text { Kode Tutur } & \text { : Bahasa Sumbawa } \\ & \text { Bahasa Sasak } \\ \text { Partisipan } & \text { : A (Pemimpin grup } \\ & \text { qasidah) } \\ & \text { B,C,D, ... (sejumlah ibu- } \\ & \text { ibu anggota grup } \\ & \text { qasidah) }\end{array}$

Tujuan tutur : Membuka acara qasidahan

B : Piran mulai ne? (kapan akan dimulai?)

$\mathrm{C}$ : Aneh mulaiang oah, baeh juluan magrib.(ayolah dimulai, nanti keburu magrib)

A : Ka mulaiang. Assalamualaikum Warrahmatullahi Wabbarakatu (Mari kita mulai, assalamualikum, ....)

B, C, D, ... : Waalaikumsalam Warrahmatullahi Wabbarakatuh

A : Se ndekman te mulaiang acara qasidahan, silak batur-batur te baca basmallah "Bismillahirohmanirahim" tris fatihah untuk keluarga dan dirik dita masing-masing, tris te baca shalawat. (Sebelum kita mulaikan acara qasidahan, silahkan temanteman kita membaca basmallah "Bismillahirohmanirahim"

kemudian kita baca al-fatihah untuk keluarga dan diri kita masing-masing, kemudian kita baca shalawat)

Pada ranah ini, pertuturan seringkali menggunakan Bahasa Sasak yang bercampur dengan Bahasa Sumbawa, bahkan ketika ada ustad/ ustadzah yang memberikan ceramah agama, mereka akan menggunakan Bahasa Sasak. Hal ini terjadi karena tidak semua penduduk di wilayah itu adalah keturunan Sumbawa, ada juga yang memang orang Sasak asli. Walaupun penduduk di wilayah itu dominan adalah keturunan Sumbawa, mereka tidak serta merta menggunakan Bahasa Sumbawa untuk menghormati orang-orang Sasak yang tidak memahami Bahasa Sumbawa. Secara garis besar hampir semua penduduk di lingkungan Karang Taliwang memahami Bahasa Sasak walaupun mereka bukan orang Sasak, sementara orang Sasak sebagian besar tidak memahami Bahasa Sumbawa. itulah yang menyebabkan para ibu-ibu memilih menggunakan Bahasa Sasak pada ranah keagamaan walaupun terjadi sedikit campur kode yaitu terselipnya beberapa kosa kata Bahasa Sumbawa, Bahasa Indonesia, maupun Bahasa Arab. Seperti pada kalimat yang digunakan oleh ketua grup qasidah untuk membuka acara yaitu kosa kata Bahasa Sumbawa; tris (terus/kemudian), dita (kita); kosa kata Bahasa Indonesia "keluarga, dan, untuk" masing-masing; kosa kata Bahasa Arab; Assalamualaikum, basmallah, fatihah, dan shalawat.

\section{Ranah Pergaulan di Masyarakat}

Pada ranah ini, suasana pertuturan biasanya tidak terlalu resmi, dan masing-masing komunitas bahasa akan menggunakan bahasanya masingmasing. Seperti pada peristiwa tutur di bawah ini, percakapan antara seorang laki-laki pegawai toko dengan seorang temannya. 
Peristiwa Tutur $V$

$\begin{array}{ll}\text { Ranah } & \text { : Pergaulan dalam } \\ & \text { masyarakat } \\ \text { Lokasi } & \text { : Sebuah toko barang- } \\ & \text { barang kredit } \\ \text { Kode } & \text { : Bahasa Bali dan bahasa } \\ & \text { Indonesia } \\ \text { Partisipan } & : \text { A (seorang bapak } \\ & \text { berusia 50 tahun) } \\ & \text { B (temannya berusia 25 } \\ & \text { tahun) } \\ \text { Tujuan tutur : } & \text { Membahas keberatan } \\ & \text { dari seorang konsumen. }\end{array}$

A : Ngeremon konsumen no Man (marah konsumen itu Man)

$\mathrm{B}$ : Engkenang ndok ngeremon (Bagaimana tidak marah)

A : Ndok ye (ya begitulah)

$\mathrm{B}$ : Bos se harusne nanya dulu barangne baru kita janjikan konsumen (bos kita harusnya mengecek dulu barangnya, baru menjanjikan kepada konsumen)

A : Ye be (memanglah)

B : Harusne kenten, bi bes dua yunet ko amblas (seharusnya begitu, sampai-sampai dua unit hilang)

Pada ranah ini, percakapan diambil di lingkungan Karang Jero yang kebetulan hampir seluruh penduduknya adalah keturunan Bali dan berbahasa Bali. Diantara sesama penutur bahasa Bali mereka tetap menggunakan bahasa Bali, namun ada beberapa kosa kata bahasa Indonesia yang terselip seperti kata-kata baru, kita, janjikan, konsumen, dan unit. Suasana percakapan cukup akrab karena antara A dan B sudah saling kenal, bahkan bekerja di toko yang sama. Ketika mereka bertemu di luar toko pun mereka tetap menggunakan bahasa Bali. Topik pembicaraan adalah mengenai seorang konsumen yang membeli kulkas secara kredit, setelah barangnya diantarkan kepada konsumen ternyata ada cacatnya sehingga si konsumen protes kepada pemilik toko. Kemudian pemilik toko meminta A dan B untuk menggantikannya dengan kulkas yang baru.

\section{SIMPULAN}

Masyarakat di Lingkungan Karang Taliwang, Kecamatan Cakranegara yang terdiri dari tiga komunitas bahasa yaitu; Komunitas bahasa Sasak, bahasa Bali, dan bahasa Sumbawa menggunakan bahasa sesuai dengan siapa mereka berbicara, dalam situasi seperti apa, dan untuk tujuan apa, ditentukan oleh berbagai faktor antara lain; ranah pemakaian, situasi/suasana tuturan, bahasa yang dikuasai oleh partisipan, kedekatan hubungan antarpartisipan. Faktor-faktor itu seringkali menimbulkan munculnya campur kode.

Pada ranah pemakaian yang paling tidak resmi seperti pada ranah keluarga dan pergaulan dengan masyarakat, mereka akan menggunakan bahasa mereka masingmasing. Sedangkan dalam situasi yang setengah resmi seperti pada ranah keagamaan, masyarakat di lingkungan Karang Taliwang memilih menggunakan Bahasa Sasak, yang bercampur dengan kosa kata Bahasa Sumbawa, Bahasa Indonesia, maupun Bahasa Arab. Kecuali untuk komunitas bahasa Bali yang hampir seluruhnya beragama Hindu dalam ranah keagaamaan, mereka menggunanakan bahasa Bali. Sementara untuk ranah yang resmi seperti ranah pendidikan (di sekolah di dalam kelas) dan di Pemerintahan (Puskesmas) Bahasa Indonesia yang menjadi pilihan, jikapun terjadi alih kode ke Bahasa Sasak, Bahasa Bali atau Bahasa Sumbawa dari pengunjung Puskesmas (pasien) biasanya petugas Puskesmas tetap menggunakan Bahasa Indonesia untuk menjawab.

\section{DAFTAR PUSTAKA}

Duranti, A. 1988. "Ethnography of Speaking” dalam New Meyer, Frederick, J. Language: The Sociocultural Context Volume IV. Cambridge: Cambridge University Press: 216-228 
Grosjean, I. 1982. Lifes with Two Languages. Cambridge: Harvard University Press

Gumperz, J.J. 1964. "Language and Social Interaction in Two Communities". American Anthropologist, 66 (6): 137 154

Gumperz, J.J. dan Hymes, D. 1972. Direction in Sociolinguistics. New York: Holt, Rinehart and Winston, Inc.

Holmes, J. 1995. An Introduction to Sociolinguistics. London: Longman

Hudson, R.A. 1980. Sociolinguistics. Cambridge: Cambridge University Press

Hymes, D. 1964a. "Introduction: Toward Ethnographies of Communication" dalam American Anthroplogiest 66. Special Publication: J.J. Gumperz \& D. Hymes. (eds) The Ethnography of Communication: 1-34 (part 2)

Ervin-Tripp, Susan, M. 1972. "An Analysis of The Interaction of Language Topic and Listener" dalam Fishman Reading in The Sociology of Language. Paris: Mouton

Fishman, J. 1989. Language and Ethnicity in Minority: Sociolinguistics perspective. Clevendon: Multilingual Matters Ltd

Grosjean, I. 1982. Lifes with Two Languages. Cambridge: Hardvard University Press

Gumperz, J.J. dan Hymes, D. 1972. Direction in Sociolinguistics. New York: Holt, Rinehart and Winston, Inc.

Hymes, D. 1964a. "Introduction: Toward Ethnographies of Communication" dalam American Anthroplogiest 66. Special Publication: J.J. Gumperz \& D. Hymes. (eds) The Ethnography of Communication: 1-34 (part 2)

Mahsun. 2011. Metode Penelitian Bahasa. Tahapan Strategi, Metode dan Tehniknya. Jakarta: Rajawali Pers

Poedjosoedarmo, S. 1978. "Kode dan Alih Kode" dalam Widyaparma 15. Yogyakarta: Balai Penelitian Bahasa

Saville-Troike, M. 2003. Ethnography of Communication: An Introduction. New York: Blackwell Publishing

Wijana, I Dewa Putu. 2010. Berkenalan Dengan Linguistik. Yogyakarta: A.com Press 